\title{
Journal of Medical Microbiology \\ and Infectious Diseases
}

\section{A Survey of Crimean-Congo Hemorrhagic Fever Virus in Ticks of Shahr-e Ray, Iran, 2016-2017}

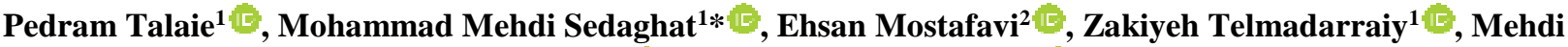 \\ Rouhani $^{3}$ (E) Mostafa Salehi-Vaziri ${ }^{4,5 *}$ (C)
}

${ }^{1}$ Department of Medical Entomology and Vector Control, School of Public Health, Tehran University of Medical Sciences, Tehran, Iran; ${ }^{2}$ Department of Epidemiology and Biostatistics, Research Centre for Emerging and Reemerging Infectious Diseases, Pasteur Institute of Iran, Tehran, Iran; ${ }^{3}$ Department of Microbiology, Pasteur Institute of Iran, Tehran, Iran; ${ }^{4}$ Research Centre for Emerging and Reemerging infectious diseases, Pasteur Institute of Iran, Tehran, Iran; Department of Arboviruses and Viral Hemorrhagic Fevers (National Reference Laboratory), Pasteur Institute of Iran, Tehran, Iran

A R T I CLE INFO A B T R A C T

\section{Original Article}

Keywords: Crimean-Congo Hemorrhagic Fever Virus, Tick, Iran

Received: Jun. 23, 2020

Received in revised form: Jun. 24, 2020

Accepted: Jun. 24, 2020

DOI: $10.29252 /$ JoMMID.8.2.56

*Correspondence

Email: m.salehi@pasteur.ac.ir

Tel: +98 2164112821

Fax: +98 2164112821
Introduction: Crimean-Congo hemorrhagic fever (CCHF) is a tick-borne viral zoonosis with a considerable fatality rate. The virus is mainly transmitted to humans and animals through the bites of infected hard ticks belonging to the genus Hyalomma. This study aimed to determine the prevalence of CCHFV in ticks in Shahr-e Ray city, one of the meat supplier counties in Tehran Province, Iran. Methods: A molecular survey was carried out on collected ticks from sheep in slaughterhouses and husbandries of Shahr-e Ray city, during 2016-17. The ticks were identified using taxonomic characteristics, and the presence of CCHF virus RNA was investigated using an RTPCR amplifying a 536 bp of the small segment of the viral genome. Results: The results of this study showed that the Hyalomma ticks were the dominant species in Shahr-e Ray slaughterhouses and husbandries. In none of the assayed ticks, RT-PCR detected CCHFV RNA. Conclusion: A considerable tick infestation with members of genus Hyalomma, among sheep in Shahr-e Ray slaughterhouses and husbandries, indicates the vulnerability of this county of tick-borne infections outbreaks such as CCHF. Therefore, applying acaricides and other preventive strategies should be adopted to control the tick population in Shahr-e Ray.

\section{INTRODUCTION}

Crimean-Congo hemorrhagic fever (CCHF) is the most widespread tick-borne viral disease of humans caused by the CCHF virus (genus Orthonairovirus, family Nairoviridae) [1]. CCHF virus is a significant public health problem; it can result in a potentially fatal hemorrhagic fever in humans (case fatality rate up to $50 \%$ ). Currently, there is no licensed vaccine or specific antiviral therapy available for this viral infection [1-3].

CCHF virus is transmitted to humans and a wide range of wild and domestic animals such as cattle, sheep, and goats by infective bites of ticks [4]. The CCHF virus RNA has been detected in at least 31 tick species [5]. Ixodidae ticks, particularly the members of the genus Hyalomma are both the principal reservoir and vector for the CCHF virus and play a vital role in the geographical distribution of the virus $[4,6]$. Apart from the infective bite of ticks, humans acquire the CCHF virus by direct contact with viremic livestock's tissues or blood. Also, reports of nosocomial transmission of the virus among health care staff are available [7, 8].
CCHF is an endemic disease in many countries in Africa, Europe, Asia, and also in the middle east [3]. The first evidence of CCHF virus circulation in Iran dates back to 1970 when serology detected CCHF antibodies in humans and livestock in different parts of the country [9]. Moreover, some studies have shown the CCHF virus infection in ticks in Iran. The CCHV infection in ticks ranged from 5\% to $11 \%$ in some areas in the north and center of Iran [10-12].

Shahr-e Ray, the southernmost urban area in Tehran Province, is one of the leading meat suppliers in the country and is home to many animal husbandries, slaughterhouses and meat processing units. Consequently, shepherds, butchers, livestock handlers, abattoir workers, and veterinary staff working in this area are at the risk of acquiring tickborne infections such as CCHF. This study aimed to determine the CCHF virus infection in ticks collected from sheep in animal husbandries and slaughterhouses of Shahr-e Ray by RT-PCR. 


\section{MATERIAL AND METHODS}

Study area. Shahr-e Rey $\left(35^{\circ} 35^{\prime} \mathrm{N}, 51^{\circ} 26^{\prime} \mathrm{E}\right)$ with a population of over 300000 inhabitants and more than 22000 $\mathrm{Km}^{2}$ is in the south of Tehran Province, the capital of Iran (Fig. 1) (https://en.wikipedia.org/wiki/Rey, Iran).

Tick collection and identification. From December 2016 to November 2017, 1249 sheep of different breeds from four animal husbandries, and one slaughterhouse in Shahr-e Ray were randomly selected and examined for tick infestation. The entire body of animals, particularly ears, nape of the neck, perineum, scrotum, and the tail base, was examined for the presence of ticks. Ticks were carefully removed from the infested animals using fine curved-tip forceps with great care. The collected live ticks were individually transferred into the sterile screwcapped labeled vials and kept under specific humidity and temperature in a cold box during transfer to Vector Biology Laboratory at Tehran University of Medical Sciences. All information about the sampling location, host, and life stage was recorded. The ticks were identified morphologically under a stereomicroscope using valid taxonomic keys [3] and then transferred to the Department of Arboviruses and Viral Hemorrhagic Fevers (National Reference Laboratory),
Pasteur Institute of Iran, for molecular detection of CCHF virus.

Viral RNA extraction and RT-PCR. Ticks were individually washed twice with PBS $1 \mathrm{X}$ (pH 7.4) crushed in 200-300 $\mu$ l of PBS 1X, and 89 pooled lysates of ticks were prepared. Total RNA extraction was performed using the RNA Easy Mini kit (Qiagen GmbH, Hilden, Germany) (Cat. No: 74106) according to the manufacturer's instructions. The extracted RNAs were stored at $-70^{\circ} \mathrm{C}$ until used. The RNA specimens were screened for CCHFV by an RT-PCR assay (One-Step RT-PCR Kit, Qiagen GmbH, Hilden, Germany) using the specific primers (F2 5'TGGACACCTTCACAAACTC-3' and R3 5'GACAATTCCCTACACC-3') that target a 536 bp of the small segment of the viral genome [13]. The $50 \mu 1$ reactions contained $5 \mu 1$ of $5 \mathrm{x}$ OneStep RT-PCR Buffer, $0.6 \mu \mathrm{M}$ each primer, $2 \mu \mathrm{l}$ dNTPs (containing $10 \mathrm{mM}$ of each dNTP), $2 \mu 1$ OneStep RT-PCR Enzyme Mix and 500 ng of viral RNA. RT-PCR amplification began with $30 \mathrm{~min}$ at $50^{\circ} \mathrm{C}$, and 15 min at $95^{\circ} \mathrm{C}$, followed by 40 cycles of $30 \mathrm{~s}$ at $95^{\circ} \mathrm{C}, 30 \mathrm{~s}$ at $50^{\circ} \mathrm{C}, 45 \mathrm{~s}$ at $72^{\circ} \mathrm{C}$ and a final extension step at $72^{\circ} \mathrm{C}$ for 10 min. RNA specimens, extracted from a previously RT-PCRpositive serum, and double-distilled water (DDW), were used as positive and negative controls, respectively, in assays.

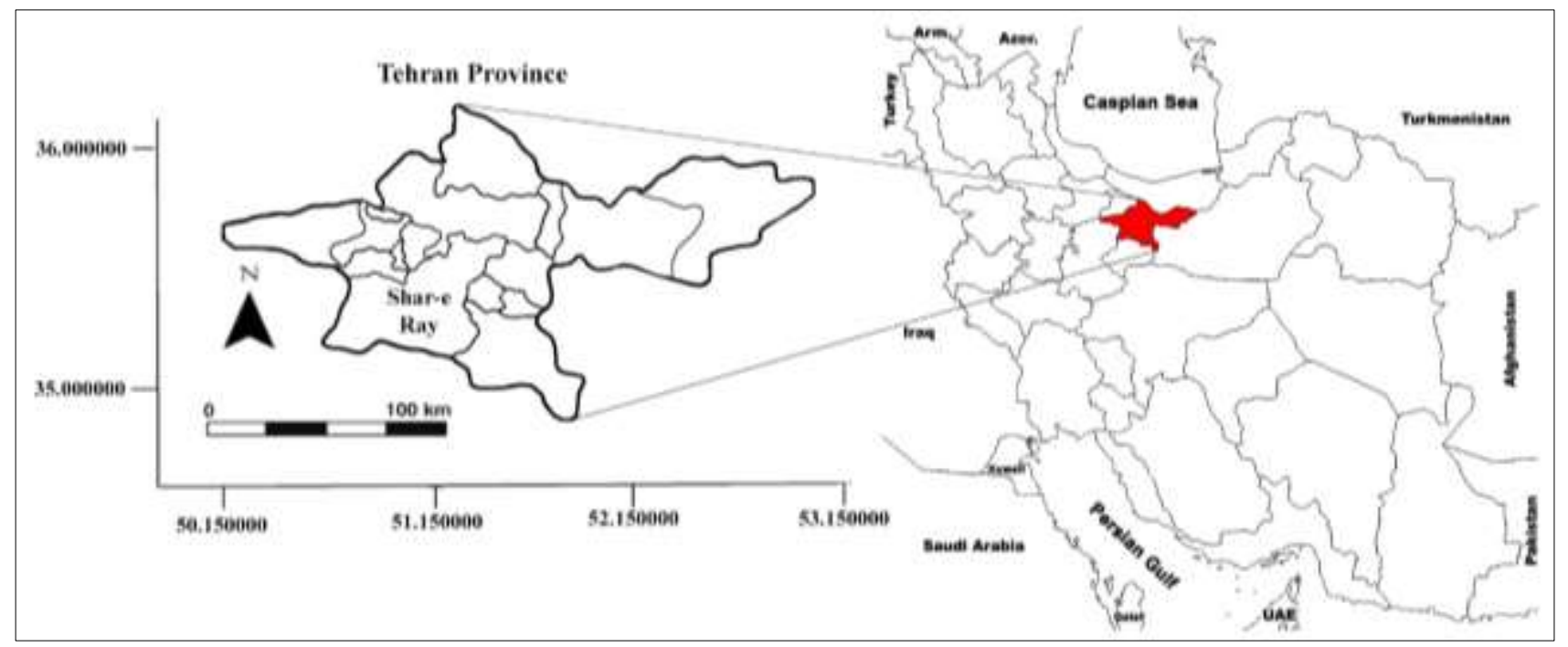

Fig. 1. Shahr-e Ray County in Tehran province, Iran

\section{RESULTS}

During seasonal sampling, out of the 1249 sheep examined, $109(8.7 \%)$ were infested with ticks. A total of 376 ticks were collected, out of which 176 (47\%) were from a slaughterhouse, and the other 200 (53\%) were from animal husbandries in Shahr-e Ray. The taxonomic approach identified ten species, nine hard tick $(97.87 \%)$, and one soft tick $(2.13 \%)$, belonging to four genera Hyalomma, Dermacentor, Rhipicepalus, and Ornithodoros (Table 1). In terms of seasonal activities, our results showed that the highest number of ticks were collected during spring (45.21\%), followed by summer (28.99\%), autumn (20.21\%) and winter $(5.59 \%)$ (Table 2).

The RT-PCR detected CCHFV in none of the 89 RNA specimens extracted from pools of tick lysates.

\section{DISCUSSION}

CCHF is a significant public health concern, with cases occurring over a wide geographic range (1). Considering the critical role of ticks in CCHF virus transmission to humans and livestock, monitoring tick infection is crucial for surveillance and disease control [6].

In this study, among 1249 sheep in 4 animal husbandries and one slaughterhouse in Shahr-e Ray, Iran, 8.7\% had tick infestation. In some areas of Iran, the variation in tick infestation among livestock, ranging from $24 \%$ to $43 \%$, and as high as $72 \%[11,14,15]$ reflects the difference in geographical features, sanitation levels and also prevention methods. 
In this study, four genera and ten tick species, including D. marginatus, Hy. anatolicum, Hy. asiaticum, Hy. excavatum, Hy. marginatum, Hy. scupense, Hyalomma sp, $O$. lahorensis, Rh. bursa and Rh. sanguineus were identified. In a similar study in Qom province, the most prevalent genus was Hyalomma (74\%) [16]. In Isfahan province, Hyalomma and Rhipicephalus were reported as the most common genera [17]. Also, Hy. anatolicum and Hy. asiaticum have been reported as two prevalent tick species in Zahedan province [18]. In Ghaemshahr County of Mazandaran Province, Rhipicephalus was reported as the dominant genus [14]. Also, in Golestan Province, Rhipicephalus and Hyalomma were reported as the main prevalent genera [15].

Table 1. Tick species collected from infested sheep in Shahr-e Ray, Iran during 2016-17

\begin{tabular}{l|lll}
\hline No. & species & Number & Frequency (\%) \\
\hline $\mathbf{1}$ & Dermacentor marginatus & 21 & 5.59 \\
$\mathbf{2}$ & Hyalomma anatolicum & 56 & 14.89 \\
$\mathbf{3}$ & Hyalomma asiaticum & 10 & 2.66 \\
$\mathbf{4}$ & Hyalomma excavatum & 1 & 0.27 \\
$\mathbf{5}$ & Hyalomma marginatum & 19 & 5.05 \\
$\mathbf{6}$ & Hyalomma scupense & 24 & 6.38 \\
$\mathbf{7}$ & Hyalomma sp & 132 & 35.11 \\
$\mathbf{8}$ & Ornithodoros lahorensis & 8 & 2.13 \\
$\mathbf{9}$ & Rhipicephalus bursa & 43 & 11.44 \\
$\mathbf{1 0}$ & Rhipicephallus sanguineus & 62 & 16.49 \\
TOTAL & & 376 & 100 \\
\hline
\end{tabular}

Table 2. The seasonal differences in tick prevalence in sheep in Shahr-e Ray, Iran during 2016-17

\begin{tabular}{l|lll}
\hline Season & No. of infested Sheep (\%) & No. of collected Ticks (\%) & Ticks per sheep (Average) \\
\hline Spring & $49(44.95)$ & $170(45.21)$ & 3.47 \\
Summer & $32(29.36)$ & $109(28.99)$ & 3.41 \\
Autumn & $23(21.10)$ & $76(20.21)$ & 3.30 \\
Winter & $5(4.59)$ & $21(5.59)$ & 2.60 \\
Total & $109(100)$ & $376(100)$ & 3.20 \\
\hline
\end{tabular}

The results of this study and similar studies [15, 19, 20] show that the frequency of ticks in spring is higher than in other seasons, which is due to vegetation, humidity, and more suitable climate conditions in temperate and warm seasons that favors the ticks' life cycle.

Based on our molecular results, the CCHFV was detected in none of the collected ticks, while Chinikar et al. reported $9 \%$ of CCHFV infection in collected ticks in Isfahan province [10]. In Hamadan Province, Tahmasebi et al. found $11.3 \%$ of CCHFV infection in 328 collected ticks in Bahar city [12]. Also, in Golestan and Sistan-Baluchistan Provinces, the CCHF virus was detected in $5.3 \%$ and $4.5 \%$ of ticks, respectively $[11,21]$. Although the result of the present study suggests the low risk of CCHF transmission via tick bites, further investigation with larger sample sizes are required to elucidate this hypothesis [22].

In this study, despite the high tick infestation of the sheep, no $\mathrm{CCHFV}$ infection was observed, indicating a low risk of CCHFV exposure in Shahr-e Ray city. However, since the ecology of tick-borne diseases such as CCHF is dynamic, an outbreak in areas where competent vectors are present can occur at any time. Therefore, necessary measures to reduce the tick infestation of animals should be implemented in this area.

\section{ACKNOWLEDGMENT}

The authors express their gratitude to the personnel of the Department of Arboviruses and Viral Hemorrhagic Fevers (National Reference Laboratory), Pasteur Institute of Iran, for their technical support. This work was funded by Tehran University of Medical Sciences, Iran, Tehran (Grant no. 9701-27-36137).

\section{CONFLICT OF INTEREST}

The authors declare that there are no conflicts of interest associated with this manuscript.

\section{REFERENCES}

1. Al-Abri SS, Al Abaidani I, Fazlalipour M, Mostafavi E, Leblebicioglu $\mathrm{H}$, Pshenichnaya $\mathrm{N}$, et al. Current status of Crimean-Congo haemorrhagic fever in the World Health Organization Eastern Mediterranean Region: issues, challenges, and future directions. Int J Infect Dis. 2017; 58: 82-9.

2. Mendoza EJ, Warner B, Safronetz D, Ranadheera C. CrimeanCongo haemorrhagic fever virus: Past, present and future insights for animal modelling and medical countermeasures. Zoonoses Public Health. 2018; 65 (5): 465-80.

3. Hoogstraal H. The epidemiology of tick-borne CrimeanCongo hemorrhagic fever in Asia, Europe, and Africa. J Med Entomol. 1979; 15 (4): 307-417.

4. Shayan S, Bokaean M, Shahrivar MR, Chinikar S. CrimeanCongo Hemorrhagic Fever Lab Med. 2015; 46 (3): 180-9.

5. Appannanavar SB, Mishra B. An update on Crimean Congo hemorrhagic fever. J Glob Infect Dis. 2011; 3 (3): 285.

6. Telmadarraiy Z, Chinikar S, Vatandoost H, Faghihi F, Hosseini-Chegeni A. Vectors of Crimean Congo hemorrhagic fever virus in Iran. J Arthropod-Borne Dis. 2015; 9 (2): 137.

7. Chinikar S, Shah-Hosseini N, Bouzari S, Shokrgozar MA, Mostafavi E, Jalali T, et al. Assessment of recombination in the $\mathrm{S}$-segment genome of Crimean-Congo hemorrhagic fever virus in Iran. J Arthropod-Borne Dis. 2016; 10 (1): 12. 
8. Chinikar S, Shayesteh M, Khakifirouz S, Jalali T, Varaie FSR, Rafigh $\mathrm{M}$, et al. Nosocomial infection of Crimean-Congo haemorrhagic fever in eastern Iran: case report. Travel Med Infect Dis. 2013; 11 (4): 252-5.

9. Chinikar S, Ghiasi SM, Hewson R, Moradi M, Haeri A. Crimean-Congo hemorrhagic fever in Iran and neighboring countries. J Clin Virol. 2010; 47 (2): 110-4.

10. Chinikar S, Ghiasi SM, Naddaf S, Piazak N, Moradi M, Razavi MR, et al. Serological evaluation of Crimean-Congo hemorrhagic fever in humans with high-risk professions living in enzootic regions of Isfahan Province of Iran and genetic analysis of circulating strains. Vector Borne Zoonotic Dis. 2012; 12 (9): 733-8.

11. Sarani M, Telmadarraiy Z, Moghaddam AS, Azam K, Sedaghat MM. Distribution of ticks (Acari: Ixodidae) infesting domestic ruminants in mountainous areas of Golestan Province, Iran. Asian Pac J Trop Biomed. 2014; 4: S246-S51.

12. Tahmasebi F, Ghiasi SM, Mostafavi E, Moradi M, Piazak N, Mozafari A, et al. Molecular epidemiology of Crimean-Congo hemorrhagic fever virus genome isolated from ticks of Hamadan province of Iran. J Vector Borne Dis. 2010; 47 (4): 211-6.

13. Aslani D, Salehi-Vaziri M, Baniasadi V, Jalali T, AzadManjiri S, Mohammadi T, et al. Crimean-Congo hemorrhagic fever among children in Iran. Arch Virol. 2017; 162 (3): 721-5.

14. Nasibeh HV, Zakkyeh T, Hassan V, Reza YEM, Morteza HV, Ali OM. Survey of tick species parasiting domestic ruminants in Ghaemshahr county, Mazandaran province, Iran. Asian Pac J Trop Med. 2010; 3 (10): 804-6.

15. Sofizadeh A, Telmadarraiy Z, Rahnama A, Gorganli-Davaji A, Hosseini-Chegeni A. Hard tick species of livestock and their bioecology in Golestan province, north of Iran. J Arthropod Borne Dis. 2014; 8 (1): 108.

16. Telmadarraiy Z, Saghafipour A, Farzinnia B, Chinikar S. Molecular detection of Crimean-Congo Hemorrhagic fever virus in ticks in Qom Province, Iran, 2011-2012. Iran J Virol. 2012; 6 (3): $13-8$.

17. Noaman V, Abdi-goudarzi M, Nabinejad A.R, Heidari M.R, Khalilifard M. Identification of hard ticks of domestic ruminants in two ecological zones of Isfahan province, Iran. J Pajouhesh Sazandegi. 2009; 77: 88-95.

18. Jafarbekloo A, Vatandoost H, Davari A, Faghihi F, Bakhshi $\mathrm{H}$, Ramzgouyan MR, et al. Distribution of tick species infesting domestic ruminants in borderline of Iran-Afghanistan. J Biomed Sci Eng. 2014; 7 (12): 982-6.

19. Nasiri A, Telmadarraiy Z, Vatandoost H, Chinikar S, Moradi M, Oshaghi M. Tick infestation rate of sheep and their distribution in Abdanan County, Ilam Province, Iran, 2007-2008. Iran J Arthropod Borne Dis. 2010; 4 (2): 56.

20.Asgarian F, Enayati AA, Amouei A, Yazdani Charati J. Fauna, geographical distribution and seasonal activity of hard ticks from Sari township in 2007-2008. J Mazandaran Univ Med Sci. 2011; 21 (83): 25-33.

21. Mehravaran A, Moradi M, Telmadarraiy Z, Mostafavi E, Moradi AR, Khakifirouz S, et al. Molecular detection of CrimeanCongo haemorrhagic fever (CCHF) virus in ticks from southeastern Iran. Ticks Tick Borne Dis. 2013; 4 (1-2): 35-8.

22. Khakifirouz S, Mowla SJ, Baniasadi V, Fazlalipour M, Jalali $\mathrm{T}$, Mirghiasi SM, et al. No Detection of Crimean Congo Hemorrhagic Fever (CCHF) Virus in Ticks from Kerman Province of Iran. J Med Microbiol Infect Dis. 2018; 6 (4): 108-11.

\section{Cite this article:}

Talaie P, Sedaghat MM, Mostafavi E, Telmadarraiy Z, Rouhani M, Salehi-Vaziri M. A Survey of Crimean-Congo Hemorrhagic Fever Virus in Ticks in Shahr-e Ray, Iran, 2016-2017. J Med Microbiol Infect Dis, 2020; 8 (2): 56-59. DOI: 10.29252/JoMMID.8.2.56 